Article

\title{
Integrated Resource Planning for Urban Waste Management
}

\author{
Damien Giurco ${ }^{1, *}$, Jade Herriman ${ }^{1}$, Andrea Turner ${ }^{1}$, Leah Mason ${ }^{1}$, Stuart White ${ }^{1}$, \\ Dustin Moore ${ }^{1}$ and Frank Klostermann ${ }^{2}$
}

1 Institute for Sustainable Futures, University of Technology Sydney, Ultimo 2007, Australia; E-Mails: jade.herriman@uts.edu.au (J.H.); andrea.turner@uts.edu.au (A.T.); nosam.m.hael@gmail.com (L.M.); stuart.white@uts.edu.au (S.W.); dustindm@gmail.com (D.M.)

2 Full Circle Advisory, Sydney Wahroonga 2076, Australia;

E-Mail: frank.klostermann11@gmail.com

* Author to whom correspondence should be addressed; E-Mail: damien.giurco@uts.edu.au; Tel.: +61-2-9514-4978; Fax: +61-2-9514-4941.

Academic Editor: Richard Kazmierczak, Jr.

Received: 24 May 2014 / Accepted: 23 December 2014 / Published: 28 January 2015

\begin{abstract}
The waste hierarchy currently dominates waste management planning in Australia. It is effective in helping planners consider options from waste avoidance or "reduction" through to providing infrastructure for landfill or other "disposal". However, it is inadequate for guiding context-specific decisions regarding sustainable waste management and resource recovery, including the ability for stakeholders to compare a range of options on an equal footing whilst considering their various sustainability impacts and trade-offs. This paper outlines the potential use of Integrated Resource Planning (IRP) as a decision-making approach for the urban waste sector, illustrated using an Australian case study. IRP is well established in both the water and energy sectors in Australia and internationally. It has been used in long-term planning enabling decision-makers to consider the potential to reduce resource use through efficiency alongside options for new infrastructure. Its use in the waste sector could address a number of the current limitations experienced by providing a broader context-sensitive, adaptive, and stakeholder focused approach to planning not present in the waste hierarchy and commonly used cost benefit analysis. For both efficiency and new infrastructure options IRP could be useful in assisting governments to make decisions that are consistent with agreed objectives while addressing costs of alternative options and uncertainty regarding their environmental and social impacts. This paper highlights various international waste planning approaches,
\end{abstract}


differences between the sectors where IRP has been used and gives a worked example of how IRP could be applied in the Australian urban waste sector.

Keywords: waste; resource recovery; planning; least cost; adaptive; stakeholder engagement

\section{Introduction}

Australian cities and towns face significant challenges in managing waste production, with Australians collectively generating approximately 44 million tonnes of waste each year [1]. Estimates based on existing data indicate that about half of this material is deposited into licensed landfills [1], resulting in some level of environmental damage and increased costs for businesses, consumers and government [1]. The National Waste Policy (2009) has generated a great deal of information regarding the status of waste generation, waste management and disposal in Australian states and territories. Responses to consultation from industry and government, as well as non-government organisations have revealed large disparities in practices and in the capacity to adhere to a nationally consistent standard for waste management [1].

Historically, waste management in Australia has been the responsibility of state governments and local government authorities, which have followed the example of other industrialised nations, by focusing upon collection and disposal of unwanted material as a means of reducing health risks and immediate, local environmental concerns [1,2]. Methods of disposal documented in Australia have varied from simple, small-scale technologies and approaches, such as local landfills or "tips", to backyard and municipal incineration, and disposal at sea (as was the case for the Sydney area from the late 19th century until 1932) [1,2].

As populations and rates of consumption have grown, the volume of waste produced has outstripped the capacity of cheap and readily accessible landfill sites, while community concerns about health issues associated with incineration have historically resulted in an effective state-by-state ban on its use for most waste materials (except for medical waste). In response to this development, and out of an in-principal commitment to resource recovery to avoid wasting embodied minerals, energy and water, Australian states have progressively adopted permutations of the "waste hierarchy", which aims to provide a consistent approach to reducing the amount of waste disposed to landfill [3]. Whilst the waste hierarchy is a useful means of explicitly ensuring that a range of waste solutions from reducing the waste produced through to recovery and disposal are explored, it is not sufficient to guide complex decision-making and exploration of trade-offs on waste options in individual regions.

This paper therefore explores the potential application of Integrated Resource Planning (IRP), used extensively in water and energy planning and management for decades [4], to support waste planners, policy makers, and industry in meeting the challenges of sustainable waste mitigation and management. Section 2 reviews the present context of waste-related decision-making in Australia using the more traditional waste hierarchy approach, looks at international literature on the subject and the principles outlined in the Strategic Sustainable Development (SSD) framework proposed by Robert et al. [5] that could assist in shifting waste management and planning to a more sustainable and adaptive approach. Section 3 introduces IRP, which has similar principles to the SSD framework and has been used 
extensively in the water and energy sectors in Australia and internationally. The section identifies the key IRP principles and steps and the importance of stakeholder engagement and participation. Central to the IRP process is its ability to engage with a specific context, systematically forecast demand, assess and compare a range of diverse options, and engage stakeholders in setting objectives for a system and criteria for the assessment of options and trade-offs using the principles of sustainability. Section 4 features a worked example of using IRP in an urban Australian context. Section 5 concludes by exploring some of the merits and challenges of the application of IRP to the waste sector.

\section{The Limitations of the Waste Hierarchy as a Guide to Waste Planning in the Australian Context}

\subsection{The Waste Hierarchy}

In its original form, the waste hierarchy provides a simple visual guide to the approaches that offer greatest efficiency in minimising waste to landfill. The hierarchy is represented in the form of an inverted pyramid that acts as a filter, reducing the volume of waste by successively eliminating waste from the point at which it enters a waste management system (reduce the amount actually generated and reuse materials), then through recycling materials (remove them from the stream of waste) to preventing their entry into the waste disposal process.

As shown in Figure 1, variations to the original concept, including expansion to include ideas of "avoidance", "recovery" and "treatment" have evolved in different contexts. In South Australia (Figure 1c), "sustainability" has also been included to show that sustainability generally increases as strategies work towards reduction or avoidance of waste, although this does not, as yet, include broader social and economic dimensions of employment or wealth generation.

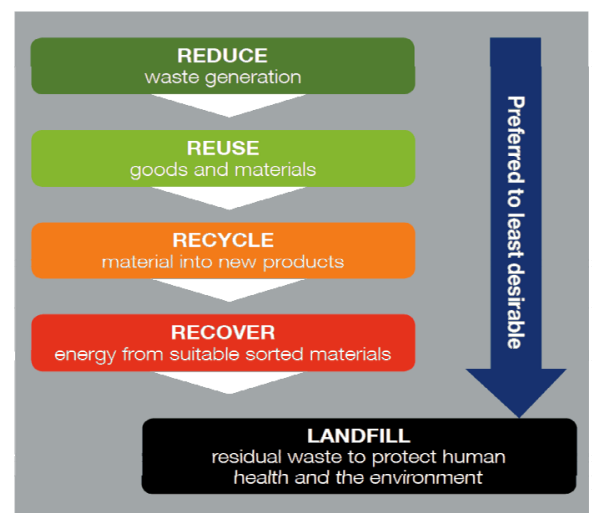

(a)

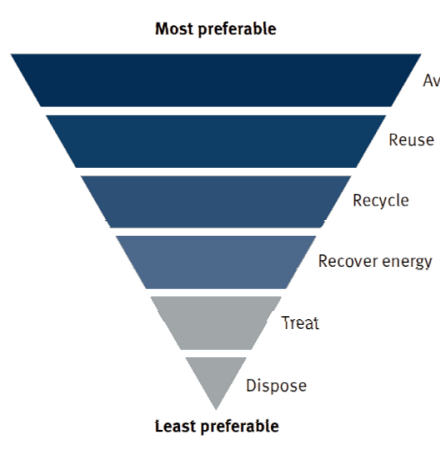

(b)

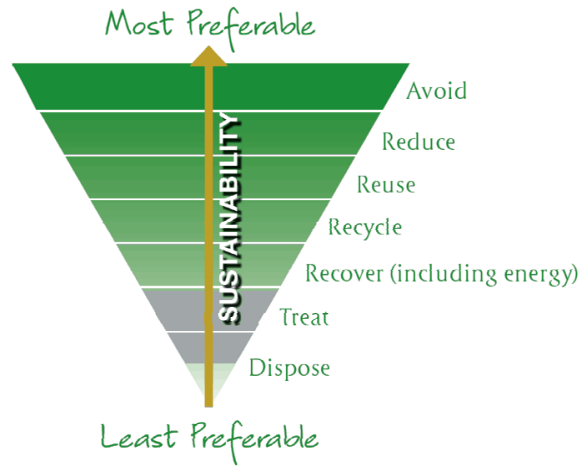

(c)

Figure 1. Waste hierarchy approach across three states/territories in Australia, from left to right, (a) Australia Capital Territory (ACT) [6]; (b) Queensland [7] and (c) South Australia [8].

\subsection{Variations in Interpreting and Applying the Waste Hierarchy}

While the broad adoption of the waste hierarchy has created much-needed organisation and direction to waste planning in Australia, it also presents a deceptive impression of regularity that obscures high variability of application and context-specific needs. 
An example of how the consistency conferred by the cross-jurisdictional use of the waste hierarchy can be misleading is well illustrated by a more detailed examination of the states/territories whose hierarchies are depicted in Figure 1. With an ambitious zero waste target, the most recent waste strategy of the Australian Capital Territory (ACT) government (2011-2025) has identified four priority outcomes (i) less waste generated, (ii) full resource recovery, (iii) a clean environment and (iv) a carbon neutral waste sector [6]. South Australia's Waste Strategy 2011-2015 has two well-articulated objectives (i) to maximise the useful life of materials through reuse and recycling and (ii) to avoid and reduce waste [8]. In contrast, Queensland (QLD) has a much shorter history of engagement with waste management that goes beyond the lowest tier in the hierarchy (dispose) but lags significantly behind states like South Australia in terms of community support and capacity (institutional, economic and physical) for measures at higher levels (e.g., lack of landfill levy). Its objectives are to (i) "drive cultural change": ... with all stakeholders...informed and empowered to participate, (ii) "avoidance and minimisation": realise all opportunities (environmental, economic, social) from maximising sustainable consumption and production, (iii) optimise economic benefits from "reuse, recovery and recycling" and (iv) "management, treatment and disposal": ...to reduce the impact of waste on human health and the environment [7].

\subsection{Supplementary Criteria and Exceptions}

Differences in high-level contextual factors, such as those raised in the previous section, become more complex when the different investments and interests of key stakeholders are also considered. An example of this is a study provided to the ACT government in preparation of the most recent revision of its waste strategy. Table 1 outlines the different interests and risks for each group involved in deploying a new waste technology [9].

Table 1. Different perspectives of industry and government participants involved in decisions about Alternative Waste Treatment (AWT) (N.B. principal means council or similar) [9].

\begin{tabular}{ll}
\hline Perspetive & Focus \\
\hline Policy developer & Broad cost and environmental effectiveness \\
Owner of facility & Cost and performance risks, approvals and siting, reliability of supply \\
Principal (metropolitan) & Political risk associated with cost and performance, community acceptance \\
Principal (regional) & Cost and performance risks, approvals and siting, reliance on landfill \\
\hline
\end{tabular}

As shown in Table 1, there are some areas of overlap in these institutional and service provision stakeholder's interests, such as "cost", "risk" and "performance" [9], which may account for the extensive use of cost benefit analysis (CBA) as an additional criteria for waste decision-making. However, in many cases the use of CBA effectively preferences options that may deliver less minimisation where there is a substantial difference in cost. It may also preference status quo infrastructure and therefore supports only incremental change. Areas of differentiation, such as environmental effectiveness for policy developers, and political risk associated with making the wrong decision for metropolitan principals, are also likely to create conflicts that cannot be resolved using the waste hierarchy. Similarly, conflicts between these groups and communities on the basis of environmental concerns or social impacts, such as changes to property values in areas surrounding 
waste management facilities [10,11], have also been important in understanding deviations from strict application of the waste hierarchy.

The issues raised above can also be seen in international waste management, as illustrated by the use of the waste hierarchy across the European Union, under the European Waste Directive [12]. As with the states and territories of Australia, the waste hierarchy acts as a foundation for waste management, across countries that are part of the EU, but this is augmented by explicit "exceptions" to the rule, where the use of other tools, such as "life cycle thinking", are recommended [13].

\subsection{An International Perspective}

Looking at the international context may assist Australia to look more broadly at tools and processes that go beyond the limitations of the waste hierarchy, which remains a useful tool but needs to be supplemented. There is a significant body of work in this area. In the early 2000s Morrissey and Browne [14] conducted an extensive review on waste management models within broader process application. The review split the models into three main approaches: those based on CBA; those based on life cycle assessment (LCA); and those based on multi criteria decision-making analysis (MCDA). The review concluded that some of the more recent models focused on integrated waste management with sustainability as a focal point but that none of the models considered the complete waste management cycle picture holistically from prevention of waste through to disposal. Most were concerned with refining the multi criteria techniques or comparing environmental factors affecting options. While many of the models recognized that sustainability should consider economic, social and environmental factors, none considered all three together or intergenerational effects. Other critical shortcomings included a lack of focus and involvement of the people who generate the waste and the broad array of stakeholders that need to be involved in decision-making for waste. The review highlighted the need for research in this area to fill the gap in terms of both models and associated processes.

Subsequent international research has filled this gap to some extent. Much has focused on improving the models to aid decision-making such as:

- integrating spatial-temporal life cycle inventory analysis with multi-criteria optimization of environmental and economic solutions and a geographical information system for a case study in the UK [15];

- minimax regret optimization analysis used in a US case study that links estimated event-based waste stream simulation (based on different environmental, economic, legal and social conditions) with possible waste management alternatives, which following optimization analyses, emphasizes the trade-offs and associated regret evaluation with predetermined scenarios assessed using MCA [16]; and

- an interval-parameter stochastic robust optimization model for supporting municipal solid waste management under uncertainty, which improves upon the existing stochastic robust optimization and interval linear programming methods and uses a hypothetical municipal solid waste management system [17].

Whilst such models are useful to deal with the complexity of waste management issues, the processes and principles within which such models are used are essential in providing guidance to 
decision-makers in how they think through the context specific waste problem, potential solutions and associated trade-offs. The international literature on principles and processes within the waste sector that go beyond the waste hierarchy and CBA are sparser. Two international examples that focus on the modelling but begin to situate the models within a broader framework focus on case studies in Taiwan [18] and Israel [19].

\subsection{From Waste Hierarchy to Sustainable Waste Management}

Another useful approach in the broader sustainability literature that provides a higher "systems" perspective, which could be tailored for the waste context, is the Strategic Sustainable Development (SSD) framework [5]. SSD has been derived from observation of multiple approaches being used internationally. It sets out basic principles that have the core aim of sustainability and show that various tools and models can be complimentary and used in parallel to achieve sustainability rather than be considered contradictory or conflicting. Table 2 provides an overview of the five levels of SSD $[5,20]$ and the process orientated questions it raises and uses them to assess existing approaches to waste management in Australia against sustainability criteria.

Table 2. Comparison of strategic sustainable development (SSD) and waste management planning in Australia.

\begin{tabular}{|c|c|c|}
\hline SSD $[5,20]$ & $\begin{array}{l}\text { Process Oriented } \\
\text { Questions }\end{array}$ & Existing Focus in Waste Management Planning in Australia \\
\hline $\begin{array}{l}\text { 1. Principles for the } \\
\text { constitution of the system. }\end{array}$ & $\begin{array}{l}\text { What is the nature of } \\
\text { the system? }\end{array}$ & $\begin{array}{l}\text { Largely ignored, role of material cycling in sustainable cities is } \\
\text { poorly understood and main focus is on solid waste (not liquid). }\end{array}$ \\
\hline $\begin{array}{l}\text { 2. Principles for a favourable } \\
\text { outcome of planning within } \\
\text { the system; principles for } \\
\text { sustainability as the desired } \\
\text { outcome. }\end{array}$ & $\begin{array}{l}\text { What is } \\
\text { desirable/sustainable? }\end{array}$ & $\begin{array}{l}\text { Implicit commitment to what is desirable as represented in } \\
\text { waste hierarchy and National Waste Policy. Conflict between } \\
\text { product-based growth economy and desire to reduce waste and } \\
\text { what is desirable at local, regional and national scales. }\end{array}$ \\
\hline $\begin{array}{l}\text { 3. Principles for the process } \\
\text { to reach the above outcome } \\
\text { sustainably. }\end{array}$ & $\begin{array}{l}\text { What processes can } \\
\text { we use to reach } \\
\text { desired outcome? }\end{array}$ & $\begin{array}{l}\text { CBA dominates, reducing consistency within and between } \\
\text { jurisdictions, indicating that the waste hierarchy is insufficient } \\
\text { as a guide for decision-making. This is where IRP can be used. }\end{array}$ \\
\hline $\begin{array}{l}\text { 4. Actions and concrete } \\
\text { measures. }\end{array}$ & $\begin{array}{l}\text { What actions will we } \\
\text { take? }\end{array}$ & $\begin{array}{l}\text { Actions and concrete measures for waste management have } \\
\text { been taken with limited or no consideration of steps } 1-3 \text {. Actions } \\
\text { are often therefore "end-of-pipe". Increased production of waste } \\
\text { has not been matched by an increased ability to manage it. }\end{array}$ \\
\hline $\begin{array}{l}\text { 5. Tools and metrics to } \\
\text { monitor and audit. }\end{array}$ & $\begin{array}{l}\text { How will we measure } \\
\text { progress? }\end{array}$ & $\begin{array}{l}\text { There has been insufficient commitment to measuring and } \\
\text { monitoring; available data is inconsistent and inaccessible across } \\
\text { jurisdictions, inhibiting good planning. }\end{array}$ \\
\hline
\end{tabular}

As shown in Table 2, the existing approaches used in Australia provide insufficient guidance for addressing aspects of sustainable waste management. This is explored in more depth in Seadon's [20] study using both the waste hierarchy and SSD framework to consider waste in New Zealand's dairy industry. The paper concludes that while a waste management hierarchy is a "useful" and "systematic" 
form of guidance, it is limited in incorporating "context" and "combinations of options", and is only one of several "tools" required for "a holistic approach to waste management" [20].

The contrast between SSD and the existing approaches used in Australia is perhaps best understood in terms of the kinds of questions that each asks about the waste management task.

As shown in Table 2, the first step in SSD looks at the systems involved and the boundary being considered, while the waste hierarchy asks no explicit questions about context or boundaries. Step 2 in SSD considers the sustainability objectives of the waste management system being established, whereas the primary objective of the waste hierarchy is minimisation. Step 3 identifies the processes that are best suited to the system (identified in Step 1), and the objectives (identified in Step 2). From this actions to meet the objectives can be developed (Step 4) and ways to monitor progress over time established (Step 5). The process oriented question arising from the waste hierarchy and associated CBA, that is often used as a supplementary criterion, act as a filter that successively asks specific questions about materials and the processes that might exist to divert them from disposal as a waste. It proceeds in a singular direction from "avoidance" to "disposal" thus reducing the opportunity for strategic and more nuanced comparisons of options, which could result in a more favourable sustainability outcome. As noted previously, there has been extensive use of the waste hierarchy in combination with CBA in Australia, and this has generally been applied to options at one level before proceeding to the next.

In the SSD framework each step contextualizes the next and can be referred to where there are conflicts or uncertainties about ways and means. This approach addresses issues raised in the previous section, in that it considers context at several levels, and is open to meaningful engagement by stakeholders. Addressing increasing complexity in waste management requires a process (Step 3 in the SSD framework) that can incorporate a wide range of concerns, media, impacts, stakeholders, and circumstances in a flexible decision-making approach. This reveals the weakness of the waste hierarchy as a decision-making schema and the need for a more detailed and adaptive approach that incorporates the principles of SSD.

Interestingly IRP, which has been used as a best practice planning and management approach in the energy and water sectors in the US for over 30 years [21-23] and Australia for over a decade [4,24], has very similar principles to SSD at heart. The principles and more detailed steps of IRP and potential application to the waste sector are explored in the following sections.

\section{Overview of Integrated Resource Planning}

\subsection{The Key Principles of IRP}

The key principles of IRP, introduced here with reference to its extensive application in long term planning in the urban water sector include [4]:

- Service provision-This principle recognises that it is the service that is required (e.g., in water the clean clothes and aesthetically pleasing gardens) and not the water itself. This ultimately leads to the fundamental principle that a kilolitre of water saved per year is equivalent to a kilolitre supplied, allowing options which reduce water demand or build new 
infrastructure to provide water are assessed at once, thus overcoming a historical bias towards building new infrastructure to meet demand growth.

- Detailed demand forecasting - Disaggregation of demand into water end uses and sectors (e.g., household toilets and showers and commercial and industrial properties) enables detailed forecasting of demand but also provides an insight into conservation potential for options development from changed technologies and behaviours.

- Consideration of a broad spectrum of viable options that satisfy service needs-For water this means water efficiency, source substitution, reuse and supply options are all considered including a mix of both measures and instruments (economic, regulatory and educative).

- Comparison of options using a common metric, boundary and assumptions - In this way the economic analysis ensures that the service provider supplies services at the lowest cost to society as a whole. The common metric, the "levelised" or "unit" cost is measured for water in present value \$/kilolitre for the multiple capital and operating costs and benefits that affect the multiple stakeholders involved in the implementation of each option. The common boundary means decision-makers consider benefits and externalities such as energy, greenhouse gases, social, environmental and risk issues for all options equally using the same basic assumptions such as discount rate and timeframe.

- A participatory process - This principle recognises that service provision interacts with many other facets of natural resource management, urban development and consumer preferences. Hence the involvement of a diverse group of stakeholders at particular parts of the planning process will be necessary to identify and respond to multiple needs and objectives.

- Adaptive management - The high emphasis on iteration means that the planning process is considered an on-going learning process in which initiatives are decided upon, implemented and evaluated in repeated cycles. In this way short-term needs are addressed, at the same time as ensuring movement towards desirable long-term outcomes. It also helps to minimize the risk of investment in large infrastructure that may not be fully utilized for many years.

\subsection{Experience of IRP in Other Sectors}

IRP has been applied to planning and management in the water, energy and transport sectors for several decades both in Australia and internationally.

For example, the water sector faces many new challenges in the twenty-first century such as more extreme climate variability, environmental constraints, societal expectations and economic drivers which have led jurisdictions to re-assess the use of large-scale rain dependent dams as well as rivers and ground water as the preferred options for additional supply. Traditionally, water planning has entailed building new supply to meet demand. However, in contrast, as identified in the principles, IRP treats a litre of water saved through efficiency or supplied through new infrastructure as equally useful in meeting the supply-demand balance for a city. A transparent comparison of options based on \$/kilolitre and other sustainability criteria are used to determine the most effective means of providing water services to customers at the lowest cost [24]. This approach leads to the uptake of a diverse portfolio of water efficiency, potable source substitution, reuse and supply options and has become central to effective and sustainable water planning [4]. As water suppliers become increasingly 
service-oriented, appropriate levels of service must be determined in consultation with communities. As an open, participatory, strategic planning process, emphasising least cost analysis of options for meeting service needs, IRP has been shown to help water utilities negotiate challenges facing the sector and better meet the needs of all stakeholders involved [4,25].

The use of IRP in the Australian water sector has grown substantially over the past decade, mainly due to the difficulties associates with the Millennium drought and failure of large rain dependent sources of water across the country, such that in 2009 the National Water Commission officially recommended IRP as the basis for sustainable urban water planning $[25,26]$.

Similar to the water sector, traditional planning for energy has focused on increasing supply where utility planners would project future demand and select from the options of increasing supply to meet their projections. As for water, the energy sector is beset by numerous challenges associated with managing supply and maintaining transmission and distribution networks as demand for energy increases [27] or decreases and the trend to decentralised over centralised infrastructure progresses. In some cases, the projected costs of increasing supply are greater than what utilities and jurisdictions can meet.

By employing IRP, utilities can determine the least cost options that enable electricity services to be maintained and account for avoiding or minimising the externalities associated with increasing supply, as D'Sa [27] explains:

"IRP can identify a series of the most cost effective options, from the array of available generation technologies and transmission upgrades, as well as end use efficiency improvements and other demand side management (DSM) measures. This is because the costs of delivering and saving a $\mathrm{kWh}$ of electricity - from improved lighting retrofits or centralised thermal generation plants or decentralised biomass generation facilities - are compared on a "level playing field". IRP is therefore technologically neutral, treating deferred or avoided end use demand as equivalent to "delivered supply of electricity."

Table 3 illustrates the usefulness of IRP as a robust approach with a well-developed history of application in various sectors. In fact, IRP can be traced as far back as the 1970s in the US [28] to the work on future energy planning looking at new supply and energy efficiency to meet demand. Additionally, it highlights the challenge of the diverse range of stakeholders present in the waste sector compared, for example, to electricity and water where often one utility controls supply all the way to customer sales.

As can be seen in the comparison made in Table 3, the waste sector may be more diverse, across all categories, than the areas in which the approach has been historically applied. When presented with the idea of applying IRP to the waste sector in Australia, participants in a government and industry stakeholder workshop [29] agreed on the potential of IRP as a future tool for the waste sector. Stakeholders indicated that a successful translation of IRP to waste would require:

- recognition of both the need for economic rationalism for Treasury and translating value for community;

- $\quad$ sustainability to support community, be measurable and confidence inducing; and

- policy to recognise diversity and the need for IRP to deal with the diversity present in the waste sector that may be less prevalent in the water and energy sectors in which it has been applied to date. 
Table 3. Integrated resource planning (IRP) application across various sectors.

\begin{tabular}{|c|c|c|c|c|c|}
\hline & Energy & Electricity & Water & Transport & Waste \\
\hline Unit of focus & $\begin{array}{l}\text { Energy (electricity, } \\
\text { gas, renewable) PJ }\end{array}$ & $\begin{array}{l}\text { Electricity only } \\
(\mathrm{kWh})\end{array}$ & Potable water (ML) & No of trips, VKT & $\begin{array}{l}\text { Tonnes waste } \\
\text { generated }\end{array}$ \\
\hline $\begin{array}{l}\text { Challenges to } \\
\text { using an IRP } \\
\text { approach }\end{array}$ & $\begin{array}{l}\text { System boundary } \\
\text { (i.e., all energy needs } \\
\text { for a city: heating, } \\
\text { stationary energy or } \\
\text { also transport) }\end{array}$ & Simplest & $\begin{array}{l}\text { Recycled water } \\
\text { demand, fit for } \\
\text { purpose water }\end{array}$ & $\begin{array}{l}\text { The number of trips to } \\
\text { "supply service to a } \\
\text { city" is unclear-how } \\
\text { many trips should be } \\
\text { allocated in a resource } \\
\text { efficient city }\end{array}$ & $\begin{array}{l}\text { Waste types; } \\
\text { Waste per person in a } \\
\text { resource efficient city } \\
\text { is unclear }\end{array}$ \\
\hline $\begin{array}{l}\text { System } \\
\text { boundaries }\end{array}$ & Multiple companies & $\begin{array}{l}\text { Electricity utilities } \\
\text { (one company) } \\
\text { can often deal } \\
\text { with supply and } \\
\text { customer demand }\end{array}$ & $\begin{array}{l}\text { Water utilities (one } \\
\text { company) can often } \\
\text { deal with supply and } \\
\text { customer demand, } \\
\text { thus cost savings from } \\
\text { demand management } \\
\text { can offset supply } \\
\text { augmentation }\end{array}$ & $\begin{array}{l}\text { Multiple transport } \\
\text { modes }\end{array}$ & $\begin{array}{l}\text { Diverse players along } \\
\text { supply chain from } \\
\text { product designers and } \\
\text { builders to waste } \\
\text { recyclers and landfill } \\
\text { operators - incentives } \\
\text { not aligned }\end{array}$ \\
\hline Example & $\begin{array}{l}\text { New Hampshire, USA } \\
\text { requires electrical } \\
\text { utilities to file a } \\
\text { biannual "Least Cost } \\
\text { Integrated Resource } \\
\text { Plan" [30] }\end{array}$ & $\begin{array}{l}\text { Various examples } \\
\text { of energy and } \\
\text { electricity IRP } \\
\text { modelling in } \\
\text { Australia and } \\
\text { internationally [31] }\end{array}$ & $\begin{array}{l}\text { Various short (drought) } \\
\text { and long term water } \\
\text { planning strategies in } \\
\text { Australia }[4,24,25]\end{array}$ & $\begin{array}{l}\text { Reframing urban } \\
\text { transport decision } \\
\text { making }[32,33]\end{array}$ & \\
\hline $\begin{array}{l}\text { Dominant } \\
\text { stakeholders }\end{array}$ & Government, utilities & Utility & $\begin{array}{l}\text { Utility, customers, } \\
\text { water appliance } \\
\text { manufacturers, } \\
\text { Government }\end{array}$ & $\begin{array}{l}\text { Transport Operator, } \\
\text { users, government }\end{array}$ & $\begin{array}{l}\text { Local government, } \\
\text { federal and state, } \\
\text { government, } \\
\text { businesses, } \\
\text { householders, } \\
\text { individuals, waste } \\
\text { service providers, } \\
\text { waste transporters, } \\
\text { product manufacturers }\end{array}$ \\
\hline
\end{tabular}

\subsection{Translating IRP to the Waste Sector}

As IRP has been used for several decades and for various sector applications already the steps used vary slightly according to the application but consistently follow the principles highlighted in Section 3.1. The following eight steps have been designed to consider how IRP might be translated to the waste sector [34].

\subsubsection{Identify Key Drivers and Objectives (Step 1)}

Information about the context of the decision-making and management and generation of waste (Step 1 in the SSD framework) can come from different sources. Questions that are useful in this step relate to both the key local and global pressures and how they might change over time. For example this might be transport distances to landfill, landfills reaching capacity or introduction of product stewardship schemes.

The objectives of the process (Step 2 in SSD) can be defined with stakeholders (e.g., reduce generation of waste, minimise waste to landfill, create a "tidier" town, create jobs). 


\subsubsection{Define System Boundary (Step 2)}

Defining the system boundary is an important part of the context for decision-making, and should be defined in terms of the space (e.g., city, region, local government area) as well as the time over which the decision-making is valid. It is recommended that the planning horizon considered should be approximately 25 years or longer. Broad consideration of options should include the production and consumption system, to ensure waste avoidance and waste management are both included. Transfers of waste impacts to air and water, or as solid waste to other geographical areas could also be considered in the system boundary definition.

\subsubsection{Analyse Size and Nature of Current and Future Waste and Material Flows through the} System (Step 3)

Analysis of existing waste material flows provides the "baseline" for understanding the task that is currently being performed by the waste management system. This should include both pre and post consumption waste materials between and within sectors. From this baseline, rates of waste generation can be modelled (increased, maintained or decreased) based on different assumptions about drivers, changes to boundaries and waste "catchments" and legislation/regulation. By breaking the waste flows down into various sectors and having a more detailed appreciation of the waste and material flows and how they might change over time enables decision-makers to begin to see where options can be used across the sectors.

\subsubsection{Options Identification and Characterisation (Step 4)}

Identify waste management/avoidance measures and their potential capacity. Step 4 identifies management and avoidance measures that are suitable to the objectives identified with stakeholders, the system boundaries and other contextual factors. Available options are assessed for their capacity to make a difference to the baseline and future waste flows. Amongst these will be specific resource recovery, avoidance, and Alternative Waste Treatment (AWT) technologies. However there is also potential for policy instruments, such as a public awareness campaign, the charging of a levy, or a container deposit scheme initiative, to play a role in creating a future reduction in some waste flows. All of these options (from avoidance to disposal) will be considered singly, and in various combinations prior to undertaking an analysis of the likely costs.

\subsubsection{Estimate Option Costs and Determine Unit Costs (Step 5)}

In Step 5, unit costs for each of the measures identified in the previous step should be calculated across the whole life cycle. This costing covers real and avoided costs as well as economic, environmental and social costs. It also considers costs to all stakeholders, both at the present time and in the future. Stakeholder advisory groups can be consulted to decide which of these costs are monetised and which will be assessed qualitatively. Once these option costs have been determined, "unit costs" (\$/tonne) for each option can be calculated for use in a comparison of the cost effectiveness. Unit costs are assessed and ranked by developing supply curves showing the lowest to highest unit costs of individual options. 


\subsubsection{Select Portfolio of Options to Meet Objective (Step 6)}

Step 6 is an option selection process that can be undertaken in various ways. Two examples provided here are:

(1) a preliminary deliberation on options which should be ruled out of consideration based on environmental and social criteria, and then a final deliberation on remaining options based on least economic cost [35]; and

(2) all options are assessed on sustainability criteria defined earlier in the process, and this information becomes an input to a multi-criteria analysis involving relevant stakeholders.

\subsubsection{Develop Implementation, Monitoring and Evaluation Plan (Step 7)}

Step 7 develops a plan for implementing the chosen options as part of an adaptive management strategy. This strategy includes a monitoring and evaluation plan to ensure data is collected on (a) performance of the chosen options and (b) whether the performance is sufficient for progress towards meeting targets in a changing context. In many IRP applications pilots are designed at this stage to test the implementation of new options, which can then be evaluated prior to full roll out.

\subsubsection{Monitoring and Evaluation (Step 8)}

An assessment that uses data specified in the monitoring and evaluation plan should be undertaken at least once every five years to ensure that the strategy and the options continue to meet the objectives of the waste management strategy as contexts change.

\subsection{Stakeholder Engagement and Participation}

As an ideal, the IRP process should include at least two advisory groups-one related to engagement and the other relating to technical matters as shown in Figure 2. In a number of the IRP steps citizens and stakeholder groups can be drawn upon to provide guidance about the suitability of the information being used in the process, as well as their views about the feasibility and/or acceptability of different options. The role of the Engagement Advisory Group (EAG) is to plan the process of community and stakeholder engagement. This group might include invited community engagement researchers and practitioners, as well as representatives from associations who have an interest in seeing effective community engagement take place. Examples include community service or equity groups, as well as associations such as the International Association of Public Participation. This group would help establish the terms of a successful engagement, identify stakeholders, and provide guidance for the design of specific processes to be used for engagement. The EAG provides expert advice on how to design a broader community engagement process but should not be considered a substitute for broader engagement.

In parallel, a Technical Advisory Group (TAG) brings together knowledge regarding the technical issues associated with waste management context and options. Input from a TAG can be used to help inform the community engagement process - for example by identifying key facts and background reading that might be important for deliberations by community and other stakeholders. 


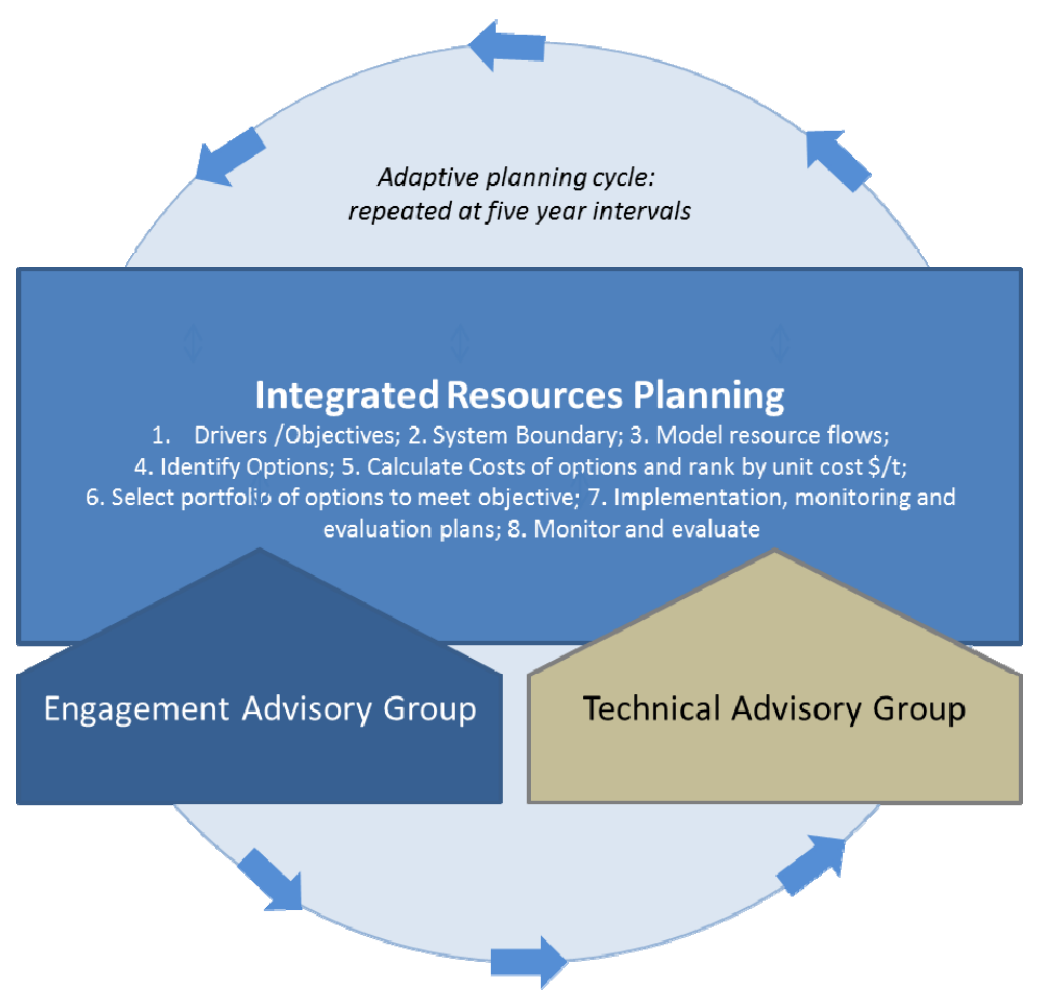

Figure 2. Adaptive planning cycle of Integrated Resource Planning (IRP) with stakeholder/technical input.

Figure 3 illustrates an IRP process with a high level of stakeholder engagement. Different steps may include more or less extensive consultation, and deliberation, with community and other stakeholders. Although each of the options outlined in Figure 3 could be undertaken with small or large group consultation, they may also be used to validate and test acceptance of decisions and assumptions made by an internal working group or consultants.

It should be acknowledged that the degree of community influence on decision-making will vary between situations and is to be expected. This issue, that is, transparency about the role of community inputs in the decision-making process, relates to the core public participation principles of "Transparency and Trust" and "Impact and Action" [36]. Good community engagement will see initiating institutions (whether state government, regional groupings of councils, or individual local governments undertaking waste planning) being explicit about where the decision-making power sits, and to what degree the community (citizens and stakeholders) will have an input into the final decision. It is important for transparency to be clear about the stages that may take place in a decision-making process, including those which will take place after a community engagement process to influence the final decision. For example when an Executive Committee, State Environment or Planning Authority, or Minister will make the final decision, based on a recommendation or suite of options submitted by the initiating organization, which in turn was shaped by community engagement. Public participation in the process also provides an opportunity for government to explain the decision-making mechanisms for waste and resource recovery, including the interplay between governing institutions.

Objectives for the waste management program, and criteria for economic, social and environmental impacts and benefit are identified at the beginning of the decision-making process and may be incorporated directly into the monitoring and evaluation plan developed in Step 8. There may also be 
further consultation to ensure that these are still the most appropriate, given the decisions that have been made.

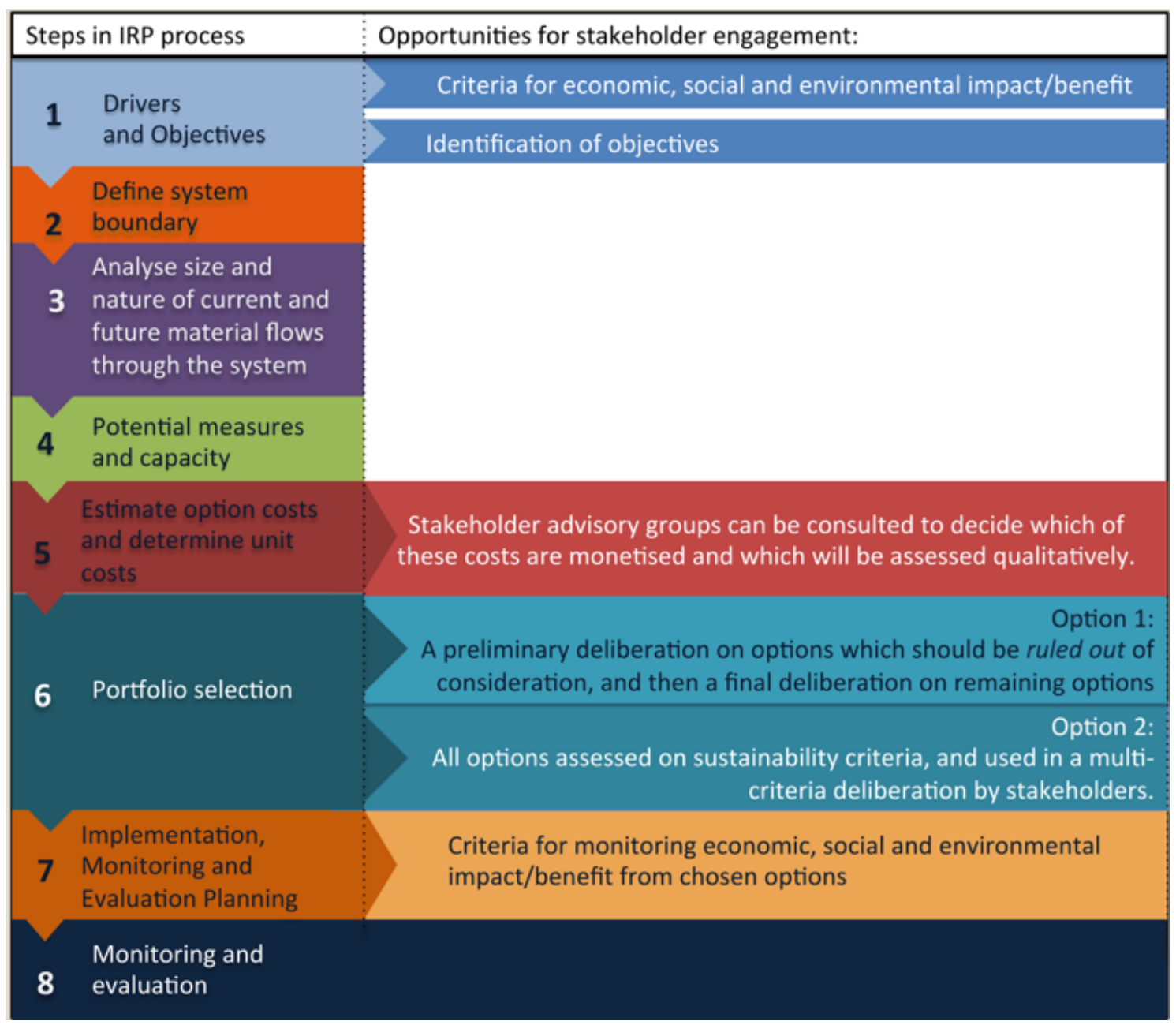

Figure 3. Engagement with stakeholders and advisory groups by process step.

\subsection{The Case for Greater Participation in Waste Management Planning}

While significantly more extensive than many existing processes, engagement with stakeholders in this way is proposed as being particularly important for an IRP process for waste management planning, due to the high levels of risk that are often associated with high cost infrastructure investments. Recent research undertaken on future waste management and landfills indicates that new investments in waste management systems are now becoming sufficiently large and costly to benefit from a similar approach.

An assessment of the barriers to "the uptake of innovation and new waste processing technologies" undertaken as part of the research and consultation around the National Waste Policy development process [37] found four main non-market barriers, namely:

- the requirement for more co-operation between councils;

- a distrust of new and unproven technologies;

- a fear of incineration; and

- reservations about making a long-term commitment to inappropriate or out-dated technology. 
This report also noted that considerable amounts of money are involved in establishing and operating AWT facilities [37].

Stakeholders from government, industry and NGO sectors, interviewed by the authors of this paper in 2011 [38], also raised similar concerns. Participants highlighted that the effectiveness of different disposal and mitigation options are dependent on the local context, including the political landscape, regulatory requirements, physical environmental conditions, geographical challenges (e.g., distances in Western Australia, and lack of markets in Tasmania) and different challenges in rural and urban contexts [38].

The lattermost of these concerns can also be seen in the Riverina Eastern Regional Organisation of Councils Submission to A National Waste Policy [39]:

"Too often our members have found that policy decisions which can be easily implemented in metropolitan regions, where there are multiple service providers, cannot be implemented at reasonable cost in rural and regional locations. Fewer service delivery options means less competition, transportation distances almost always impact on the financial viability of service delivery and lack of a critical mass of market and/or product often means that sustainable delivery cannot be achieved." [39].

The need and appreciation of stakeholder engagement was also raised by this organisation, which congratulated the taskforce implementing the policy on its decision to host a regional consultation:

"We encourage the Taskforce and the Department to continue to consult widely on the development of the Plan as it is only through a genuine consultative process that waste management issues can be successfully addressed." [39].

The following section describes an illustrative worked example of IRP for waste management and mitigation in Canberra, Australia. The data utilised in this example are taken from documents that have been published by the government of the ACT, which governs Canberra, and are used to illustrate the potential for using IRP in the waste management sector with actual data.

\section{A Worked Example to Illustrate IRP in an Australian Urban Waste Context}

\subsection{The Australian Capital Territory (ACT)}

Comprehensive waste data sets in Australia are limited, but the ACT has been active, for many years, in auditing to determine progress towards a world first target of "no waste" [40]. Annual statistics are compiled on waste disposal to landfill and resource recovery levels [40]. Data on waste disposed to landfill were derived from the ACT NOWaste weighbridge transaction database. Data on reuse, resource recovery and recycling derived by surveying approximately 100 organisations involved in these activities [40]. The data capturing infrastructure and processes in the ACT have allowed other organisations to undertake various feasibility studies and audits $[9,41,42]$. These reports and others have been used in the creation of the illustrative worked example [34] summarised here. 


\subsection{Future Projections in the Worked Example}

The worked example depicted in Figure 4 is derived from data found in the publicly available reports "ACT Landfill Audits" [41], "Economic Modelling of Options for Waste Infrastructure in the ACT" [42] and "Australian landfill capacities into the future" [43], which were available when the worked example [34] was originally developed. The graph represents historic (2000-2010) waste supply and the waste supply projection (demand for waste management) up to 2030. It should be noted that the demarcation of the waste streams in this depiction is not demonstrative of how landfills are layered, and that the jump at 2010 reflects the change between actual data and forward projections when the analysis was conducted. The graph indicates that under a Business As Usual (BAU) scenario, around $275 \mathrm{kt}$ waste/year and rising, the ACT will have reached its approved landfill capacity of $1.4 \mathrm{Mt}$ (approximately calculated as $1400 \mathrm{kt}$ divided by an average of $275 \mathrm{kt} / \mathrm{a} \approx 5$ years) around the year 2016 .

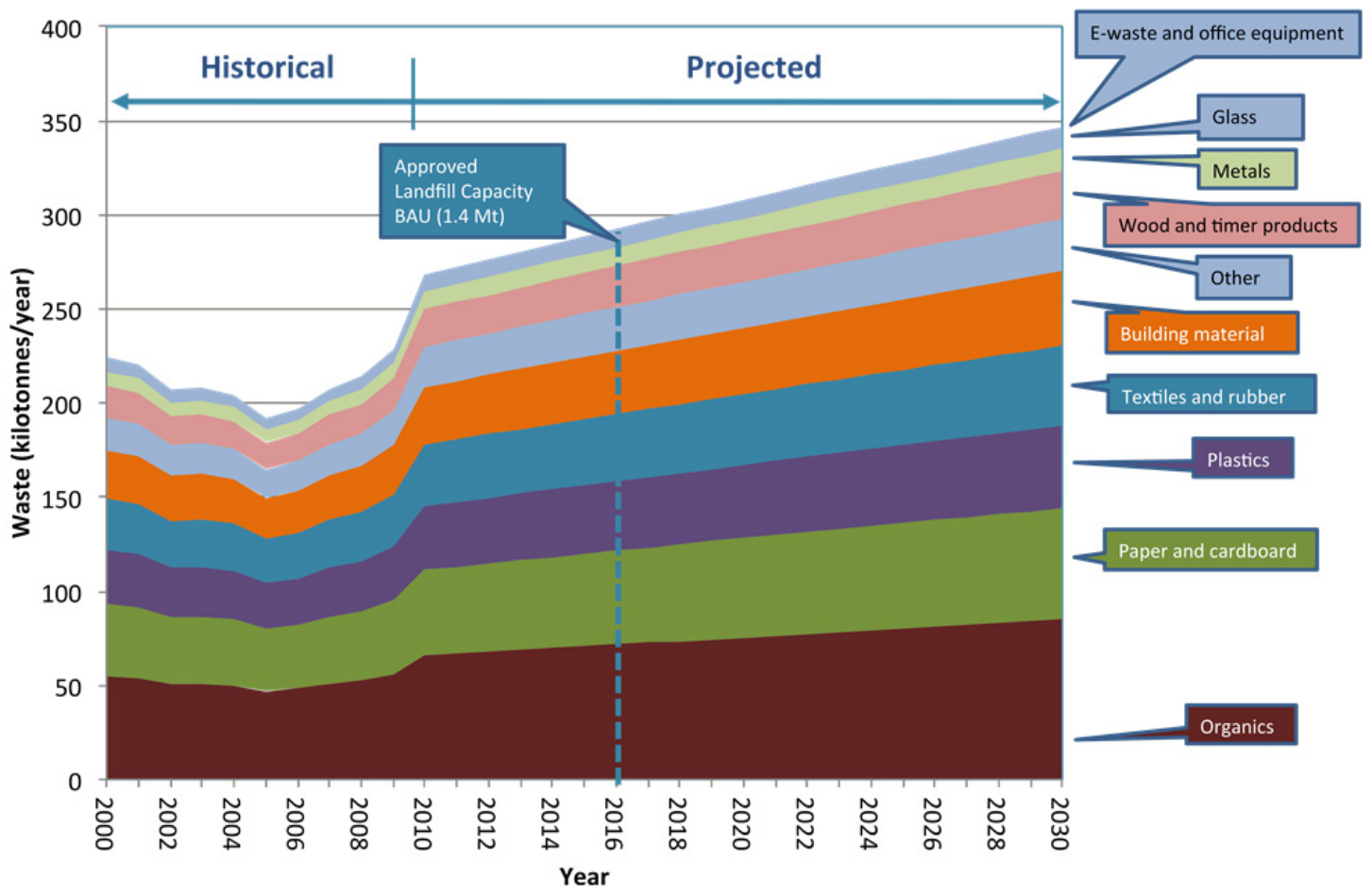

Figure 4. Waste supply projection versus approved capacity.

This projection indicates that if growth in waste generation continues as projected then existing approved landfill capacity in the ACT will be exhausted in the near future and thus options for creating additional capacity or increasing diversion options need to be considered.

\subsection{Cost Effectiveness of Future Options}

The ACT Government has been very active in testing the effectiveness of its strategies for managing and diverting waste from landfill. In 2008, prior to the release of its latest waste strategy, a review of the strategy and targets was undertaken, and a range of scenarios developed to test the economic and financial costs and benefits of different targets. For the purpose of this worked example, data compiled 
from a study by URS [42] was used to illustrate the cost effectiveness of various options (other than extending landfill) for closing the gap between waste and available capacity for managing waste.

Figure 5 presents the analysis [34] in a supply curve that illustrates the cost per tonne of the illustrative options. The least cost waste management options are presented at the left of the diagram, and plotted against the quantities of waste, which could be avoided or handled (termed "waste capacity") by each option in Canberra in the year 2030. In the case of options such as a food waste campaign, waste smart, deposit and refund for containers, the waste capacity refers to the tonnage reduction achieved by the option, whilst for Materials Recovery Facilities (MRF) and energy from waste, the waste capacity refers to the tonnage that can be handled by the option. A similar supply curve could also be drawn for 2020 (or any other year), reflecting different costs and volumes for points in time. This comparing of options relates to Step 5 in the IRP process. Note this worked example uses only costs, as investigations into associated benefits using a consistent boundary of analysis for each option were not available. Hence the reduction focused waste options would look even more favourable compared to the supply focused options if such benefits were incorporated.

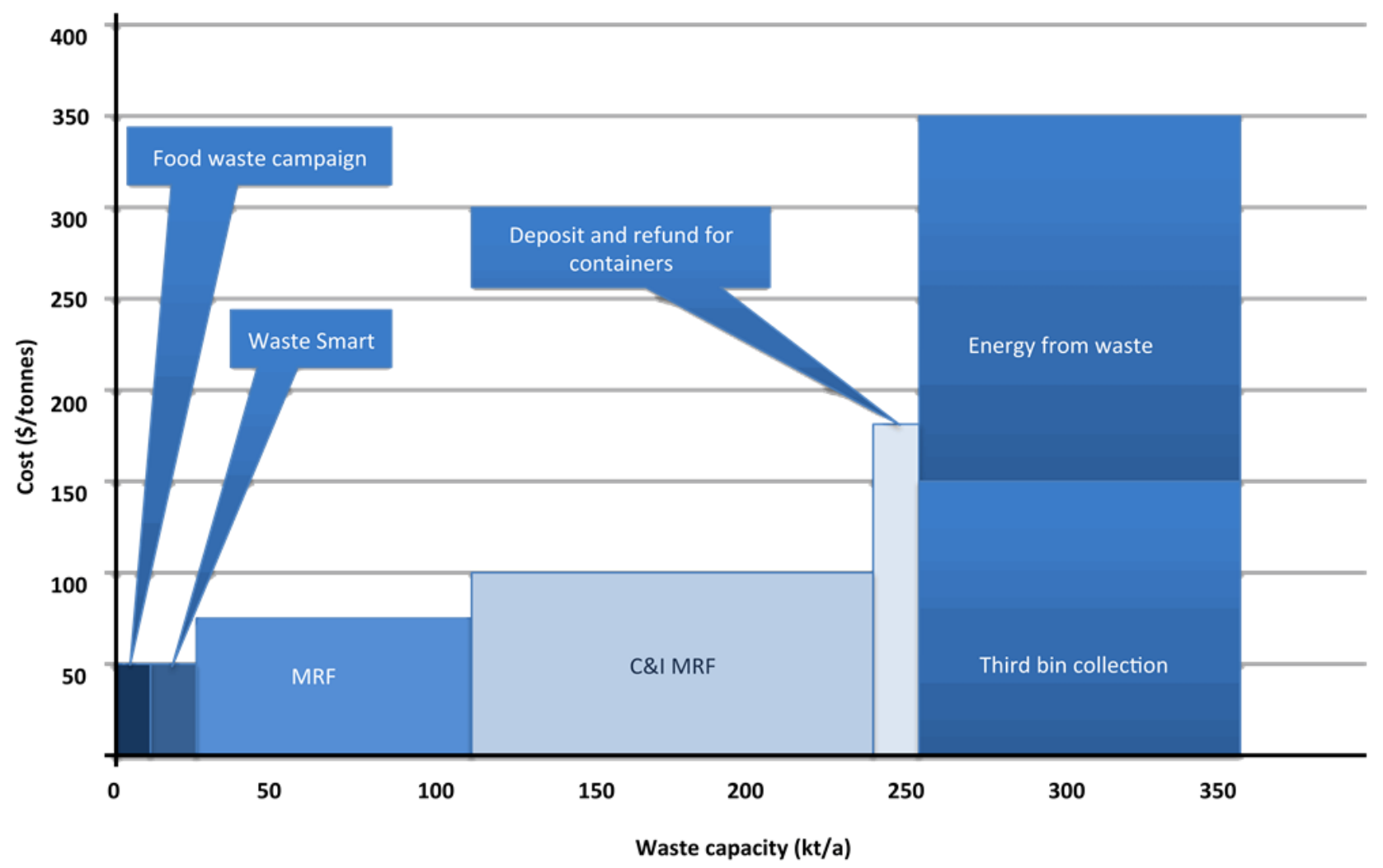

Figure 5. Illustrative supply curve for waste management options in kt/a in 2030.

In this example, IRP's capacity to assess resource recovery, disposal and waste avoidance options on an equal basis has shown that there is a great deal that can be achieved in reducing waste at relatively low cost, with a similar amount of reduction that can be achieved through much higher cost investments in energy from waste infrastructure and the provision of a third bin.

In practice, there are additional cost effective waste avoidance and mitigation options, which could be pursued which are not shown on the graph. The experience of applying IRP in the energy and water 
sectors suggests that initially avoidance or efficiency options are often poorly evaluated, leading initially to inadequate data for assessing their costs and effectiveness and reservations by decision-makers of the real extent to which such options can contribute to filling the supply-demand gap. However with its explicit focus on monitoring and evaluation embedded within the IRP process such data gradually becomes available and as has been seen in both the water and energy sectors efficiency has played a critical role in diversifying the portfolio of options used in providing services to the community.

The experience of applying this approach in other sectors has revealed that initially the options often vary by an order of magnitude due to the difficulties in assessing the savings, yield and costs of options. But even using the limited available data (with all its uncertainties) tends to lead to the same relative costs of options. As costs and waste volumes change over time, the "mix" of options used may need to change.

\section{Conclusions}

This paper identifies that the complexity of future waste planning and management requires an approach that goes well beyond the waste hierarchy and CBA approaches typically used in Australia. Looking internationally there has been considerable work on creating models that can assist in decision-making for waste but there has been less focus on guidance of the broader decision-making processes and involvement of stakeholders. The principles of the SSD framework that put sustainability as a focal point in the decision-making process, and similar and extended principles and detailed steps of IRP, could provide significant value in urban waste planning and management decision-making in Australia.

IRP shows promise in addressing the limitations of the more established approaches. The key features of IRP, namely consideration of the: context; drivers and objectives; boundary of analysis; service provision in question; detailed demand forecasting; broad spectrum of options; quantifiable and non-quantifiable costs and benefits; stakeholders and engagement processes needed; and monitoring and evaluation required - assist in creating a much needed adaptive management approach to the emerging challenges we now face.

IRP has been successfully applied in the water and energy sectors in Australia and internationally for many years, but has not yet been applied in systems with the variety of materials currently involved in the waste sector. Additional complexity comes from issues such as the different health and environmental impacts associated with each of these materials. Developing agreement about clear and achievable objectives in such circumstances will require significant mapping of issues, implications, barriers, incentives, in addition to the processes and technologies that might be used to achieve objectives. In addition, where feasible further recognition and integration of the economic and social value of the materials we discard incorporated.

IRP offers strong potential to handle the complexity of today's waste paradigm, both in terms of the number of relationships and interactions between different stakeholders, and with respect to the nature of the materials being addressed. IRP's focus on objectives and its support for exploring a wide range of alternatives simultaneously using a consistent boundary of analysis and incorporation of both quantifiable and non-quantifiable costs and benefits may be very useful in resolving issues between 
diverse stakeholder groups and be the key to a new era of more sustainable waste management in Australia.

\section{Acknowledgments}

This paper summarises some of the results from the "Landfill Futures" project carried out by the Institute for Sustainable Futures (ISF) at the University of Technology Sydney. Besides the authors, a large number of people have contributed, including researchers, members of a project reference group and participants in workshops and interviews. We are grateful to all these as well as to the CRC CARE 1 Program 4-the Social, Legal, Policy and Economic Issues Program for funding this research.

\section{Author Contributions}

Damien Giurco, Leah Mason, Jade Herriman and Dustin Moore worked on the project team for the "Landfill Futures" project and to translate the research findings from the IRP technical report into this journal article. Andrea Turner provided review and input to the paper focusing on interpretation and translation of the IRP process. Stuart White provided input to the original research concept, direction of the research and paper review. Frank Klostermann provided technical review and input to the claims developed within the paper.

\section{Conflicts of Interest}

The authors declare no conflict of interest.

\section{References}

1. Environment Protection and Heritage Council (EPHC). National Waste Report 2010; Department of the Environment, Water, Heritage and the Arts: Canberra, Australia, 2010.

2. Waste Management Association of Australia. Bioreactor Landfill Technology; Discussion Paper for Information and Comment; Waste Management Association of Australia, National Landfill Division: Sydney, Australia, 2008.

3. Gertsakis, J.; Lewis, H. Sustainability and the Waste Management Hierarchy: A Discussion Paper for EcoRecycle Victoria; RMIT University: Melbourne, Australia, 2003.

4. Turner, A.; Willetts, J.; Fane, S.; Giurco, D.; Chong, J.; Kazaglis, A.; White, S. Guide to Demand Management and Integrated Resource Planning (Update on Original 2008 Guide); Institute for Sustainable Futures, University of Technology Sydney: Sydney, Australia, 2010; pp. 1-174. Available online: https://letscrate.com/o9B (accessed on 8 December 2014).

5. Robert, K.H.; Schmidt-Bleek, B.; Aloisi de Larderel, J.; Basile, G.; Jansen, J.L.; Kuehr, R.; Price Thomas, P.; Suzuki, M.; Hawken, P.; Wackernagel, M.; et al. Strategic sustainable development-Selection, design and synergies of applied tools. J. Clean. Prod. 2002, 10, 197-214.

6. ACT Government. ACT Waste Management Strategy—Towards a sustainable Canberra 2011-2025; Environment and Sustainable Development Directorate: Canberra, Australia, 2011. 
7. Department of Environment and Heritage Protection (EHP). Waste-Everyone's responsibility: Queensland Waste Avoidance and Resource Productivity Strategy (2014-2024); Department of Environment and Heritage Protection, Queensland Government: Brisbane, Australia, 2014.

8. Government of South Australia. South Australia's Waste Strategy 2011-2015; Zero Waste SA, Government of South Australia, Adelaide, Australia, 2011.

9. Wright Corporate Strategy. ACT No Waste Strategy \& Targets: Review \& Assessment of Options (Revised Final Report); ACT NoWaste: Sydney, Australia, July 2008.

10. Costello, L.N.; Dunn, K. Resident action groups in Sydney: People power or rat bags? Aust. Geogr. 1994, 24, 67-76.

11. Cordell, D.; Moore, D.D.; Gero, A.; Herriman, J.; Mason, L. White, S. Sustainability Costs and Challenges of Waste Management and Mitigation in Australia; Institute for Sustainable Futures, University of Technology Sydney: Sydney, Australia, 2012.

12. European Commission. Being Wise with Waste: The EU's Approach to Waste Management. Available online: http://ec.europa.eu/environment/waste/index.htm (accessed on 4 January 2015).

13. Finnveden, G.; Ekvall, T.; Arushanyan, Y.; Bisaillon, M.; Henriksson, G.; Gunnarsson Östling, U.; Ljunggren Söderman, M.; Sahlin, J.; Stenmarck, Å.; Sundberg, J.; et al. Policy Instruments towards a Sustainable Waste Management. Sustainability 2013, 5, 841-881.

14. Morrissey, A.J.; Browne, J. Waste management models and their application to sustainable waste management. Waste Manag. 2004, 24, 297-308.

15. Shmelev, S.E.; Powell, J.R. Ecological-economic modeling for strategic regional waste management systems. Ecol. Econ. 2006, 59, 115-130.

16. Chang, N.B.; Davila, E. Minimax regret optimization analysis for a regional solid waste management system. Waste Manag. 2007, 27, 820-832.

17. Xu, Y.; Huang, G.H.; Qin, X.S.; Cao, M.F.; Sun, Y. An interval-parameter stochastic robust optimization model for supporting municipal solid waste management under uncertainty. Waste Manag. 2010, 30, 316-327.

18. Weng, Y.C.; Fujiwara, T. Examining the effectiveness of municipal solid waste management systems: An integrated cost-benefit analysis perspective with financial cost modeling in Taiwan. Waste Manag. 2011, 31, 1393-1406.

19. Broitman, D.; Ayalon, O.; Iddo, K. One size fits all? An assessment tool for solid waste management at local and national levels. Waste Manag. 2012, 32, 1979-1988.

20. Seadon, J.K. Integrated Resource Management. Ph.D. Thesis, University of Auckland, Auckland, New Zealand, 1 July 2010.

21. American Water Works Association. Integrated Resource Planning: A Balanced Approach to Water Resources Decision-Making; American Water Works Association (AWWA) Research Foundation by Barakat and Chamberlin, American Water Works Association: Denver, CO, USA, 1994.

22. Swisher, J.N.; de Martino Jannuzzi, G.S.; Redlinger, R.Y. Tools and Methods for Integrated Resources Planning: Improving Energy Efficiency and Protecting the Environment; UNEP Collaborating Centre on Energy and Environment, Riso National Laboratory: Roskilde, Denmark, 1997.

23. Tellus Institute. Best Practices Guide: Integrated Resource Planning for Electricity; The Energy Group, Institute of International Education: Washington, DC, USA, 2000. 
24. White, S. Demand Management and Integrated Resource Planning in Australia. In Proceedings of the Efficient Use and Management of Water for Urban Supply Conference, Madrid, Spain, 21-23 May 2001. Available online: http://cfsites1.uts.edu.au/find/isf/publications/ white2001demandmanagementAustralia.pdf (accessed on 15 January 2015).

25. Institute for Sustainable Futures, UTS. Integrated Resource Planning for Urban Water-Resource Papers; Waterlines Report Series No. 41; National Water Commission, Government of Australia: Canberra, Australia, 2011. Available online: https://letscrate.com/o9D (accessed on 8 December 2014).

26. National Water Commission. Australian Integrated Resource Planning Framework and ManualProgress; National Water Commission, Government of Australia: Canberra, Australia, 2009. Available online: http://archive.nwc.gov.au/rnws/urban/integrated-resource-planning/australianintegrated-resource-planning-framework-and-manual-progress (accessed on 15 January 2015).

27. D'Sa, A. Integrated Resource Planning (IRP), Part 1: Recent Practice for the Power Sector; International Energy Initiative (IEI): Bangalore, India, 2011.

28. Lovins, A.B. Energy strategy: The road not taken. Foreign Aff. 1976, 55, 65.

29. Herriman, J.; Asker, S.; Gero, A.; Mason, L.; Cordell, D.; Moore, D.D.; White, S. Waste Futures: Workshop Report; Institute for Sustainable Futures, University of Technology, Sydney: Sydney, Australia, 2012.

30. Scholer, K. State Analysis and Survey on Restructuring and Regulation: Final Report; Maryland Public Service Commission: Baltimore, US, 2008.

31. Dunstan, C.; Cooper, C.; Glassmire, J.; Ison, N.; Langham, E. Evaluating Costs of Decentralised Energy, Working Paper 4.3; CSIRO Intelligent Grid Research Program by the Institute for Sustainable Futures, University of Technology, Sydney: Sydney, Australia, 2011. Available online: http://igrid.net.au/resources/index.html (accessed 15 January 2015).

32. Chong, J.; Brennan, T.; McKibbin, J.; White, S. Easy Travel Strategies-Integrated Resource Planning Final Report; TransLink Transit Authority by the Institute for Sustainable Futures, University of Technology, Sydney: Sydney, Australia, 2011.

33. White, S.; Brennan, T. Reframing urban transport decision making. Rail Express 2010, 3, 87-91.

34. Giurco, D.; Moore, D.; Mason, L.; Herriman, T.; Boyle, T.; White, S. Integrated Resource Planning for Waste-Technical Report; Institute for Sustainable Futures, University of Technology, Sydney: Sydney, Australia, 2012.

35. White, S.; Fane, S.A.; Giurco, D.; Turner, A.J. Putting the Economics in Its Place: Decision-Making in an Uncertain Environment; Zografos, C., Howarth, R., Eds.; Deliberative Ecological Economics, Oxford University Press: New Delhi, India, 2008; pp. 80-106.

36. National Coalition for Dialogue \& Deliberation. Core Principles for Public Engagement. Available online: http://www.ncdd.org/pep/ (accessed on 8 December 2014).

37. GHD. Waste Technology and Innovation Study Final Report; Department of the Environment, Water, Heritage and the Arts: Canberra, Australia, 2009.

38. Gero, A.; Herriman, J.; Cordell, D.; Mason, L.; Moore, D.D.; White, S. Landfill Futures: Stakeholder Interview Summary Report; Institute for Sustainable Futures, University of Technology, Sydney: Sydney, Australia, 2012. 
39. Riverina Eastern Regional Organisation of Councils (REROC). A National Waste Policy: Managing Waste to 2020; REROC: Wagga Wagga, Australia, May 2009.

40. ACT Government. Draft ACT Sustainable Waste Strategy 2010-2025; ACT Government: Canberra, Australia, 2010.

41. APrince Consulting Pty Ltd. ACT Landfill Audits: Combined Final Audit Report; ACT NO Waste: Sydney, Australia, July 2010.

42. URS. Economic Modelling of Options for Waste Infrastructure in the ACT; Supplementary Report; 27 August 2010.

43. Hyder Consulting Pty Ltd. Australian Landfill Capacities into the Future; Department of the Environment, Water, Heritage and the Arts: Canberra, Australia, 2009.

(C) 2015 by the authors; licensee MDPI, Basel, Switzerland. This article is an open access article distributed under the terms and conditions of the Creative Commons Attribution license (http://creativecommons.org/licenses/by/4.0/). 